\title{
Outcomes following surgical management of vagus nerve stimulator-related infection: a retrospective multi-institutional study
}

\author{
Hirotaka Hasegawa, MD, PhD, ${ }^{1,2}$ Jamie J. Van Gompel, MD, ${ }^{1}$ W. Richard Marsh, MD, ${ }^{1}$ \\ Robert E. Wharen Jr., MD, ${ }^{3}$ Richard S. Zimmerman, MD, ${ }^{4}$ David B. Burkholder, MD, ${ }^{5}$ \\ Brian N. Lundstrom, MD, PhD, ${ }^{5}$ Jeffrey W. Britton, MD, ${ }^{5}$ and Fredric B. Meyer, MD ${ }^{1}$ \\ Departments of ${ }^{1}$ Neurologic Surgery and ${ }^{5}$ Neurology, Mayo Clinic, Rochester, Minnesota; ${ }^{2}$ Department of Neurosurgery, \\ The University of Tokyo Hospital, Tokyo, Japan; ${ }^{3}$ Department of Neurologic Surgery, Mayo Clinic, Jacksonville, Florida; and \\ ${ }^{4}$ Department of Neurologic Surgery, Mayo Clinic, Phoenix, Arizona
}

\begin{abstract}
OBJECTIVE Surgical site infection (SSI) is a rare but significant complication after vagus nerve stimulator (VNS) placement. Treatment options range from antibiotic therapy alone to hardware removal. The optimal therapeutic strategy remains open to debate. Therefore, the authors conducted this retrospective multicenter analysis to provide insight into the optimal management of VNS-related SSI (VNS-SSI).

METHODS Under institutional review board approval and utilizing an institutional database with 641 patients who had undergone 808 VNS-related placement surgeries and 31 patients who had undergone VNS-related hardware removal surgeries, the authors retrospectively analyzed VNS-SSI.

RESULTS Sixteen cases of VNS-SSI were identified; 12 of them had undergone the original VNS placement procedure at the authors' institutions. Thus, the incidence of VNS-SSI was calculated as $1.5 \%$. The mean ( \pm standard deviation) time from the most recent VNS-related surgeries to infection was $42( \pm 27)$ days. Methicillin-sensitive staphylococcus was the usual causative bacteria (58\%). Initial treatments included antibiotics with or without nonsurgical procedures $(n=$ $6)$, nonremoval open surgeries for irrigation $(n=3)$, generator removal $(n=3)$, and total or near-total removal of hardware $(n=4)$. Although 2 patients were successfully treated with antibiotics alone or combined with generator removal, removal of both the generator and leads was eventually required in 14 patients. Mild swallowing difficulties and hoarseness occurred in 2 patients with eventual resolution.
\end{abstract}

CONCLUSIONS Removal of the VNS including electrode leads combined with antibiotic administration is the definitive treatment but has a risk of causing dysphagia. If the surgeon finds dense scarring around the vagus nerve, the prudent approach is to snip the electrode close to the nerve as opposed to attempting to unwind the lead completely.

https://thejns.org/doi/abs/10.3171/2020.7.JNS201385

KEYWORDS epilepsy; hardware infection; surgical complication; vagus nerve stimulator

$\mathrm{T}$ HE incidence of epilepsy from all etiologies is approximately $1 \%$ worldwide. ${ }^{1}$ Approximately a third of these cases are medically refractory and may require surgical intervention. ${ }^{1,2}$ Among the variety of epilepsy surgeries, vagus nerve stimulation is an effective treatment. ${ }^{3-5}$ Overall, it has been reported that $35 \%-50 \%$ of patients have $>50 \%$ seizure reduction within a couple of months to a year from vagus nerve stimulator (VNS) implantation, with a minority becoming seizure free., ${ }^{3,6-12}$ Since its approval in 1997, VNS placement has become available worldwide and is now one of the most common procedures for medically intractable epilepsy, having been performed in more than 100,000 patients as of 2018. This number will continue to grow given that vagus nerve stimulation is now available for treatment-resistant depression. . $13-16^{13}$

Although placement of a VNS is considered minimally invasive, the possible complications are variable, including infection, vocal cord damage, laryngopharyngeal dysfunction, postoperative hematoma, carotid artery injury, aseptic reaction, cable discomfort, generator displacement, and hardware-related complications such as lead fracture, mal-

ABBREVIATIONS GR = generator removal; MSS = methicillin-sensitive staphylococcus; NTR = near-total removal; SSI = surgical site infection; TR = total removal; VNS = vagus nerve stimulator; VNS-SSI = VNS-related SSI.

SUBMITTED April 20, 2020. ACCEPTED July 14, 2020.

INCLUDE WHEN CITING Published online December 18, 2020; DOI: 10.3171/2020.7.JNS201385. 
function, or disconnection. ${ }^{1,9,17}$ In addition, VNS-related surgical site infection (VNS-SSI) has been reported at a frequency of $2.6 \%-8 \% \%^{3,9,17-20}$ and often prompts hardware removal in light of the long-established principle of surgical treatment for foreign body infection. Indeed, in many previous reports, hardware removal for VNS-SSI was dogmatically performed and was usually very effective in terms of infection control. ${ }^{3,21-25}$ However, while antibiotic therapy may not always be effective, surgical removal of the cervical electrodes carries some risk, specifically potential injury to the vagus nerve. Thus, a few studies have posed a question regarding the necessity of hardware removal; $; 6-29$ however, the data and case numbers are quite limited. The purpose of this retrospective multicenter analysis, including three affiliate tertiary care centers, was to provide insight into the optimum management of VNS-SSI.

\section{Methods \\ Patient Selection}

The study was approved by the Mayo Clinic Institutional Review Board; informed consent was not required on the basis of the minimal risk associated with the retrospective study design. From a database including cases from three of our institutions from 1997 to 2019, we identified 641 patients with 808 VNS-related implantation surgeries (596 VNS placements/replacements and 212 generator replacements) and 31 patients with 36 VNS-related hardware removal surgeries (Fig. 1). Among these cases, we identified patients who had developed VNS-SSI and included them in this study. The diagnosis of VNS-SSI was made if a patient had undergone VNS-related procedures and developed one or more signs of SSI, such as purulence, positive culture, and superficial signs including wound dehiscence, swelling, drainage, and redness. The presence of redness alone was not necessarily considered to be infection, as this could be caused by a reaction to stitches/staples or dressings.

The data included patients who had undergone multiple failed attempts to control VNS-SSI at outside hospitals and were then referred to one of the study sites. In general, if there was uncertainty about an infection, observation with oral antibiotics was first recommended. Upon confirmation of VNS-SSI, hardware removal was generally recommended, though the actual type of surgery and extent of removal were at the discretion of attending physicians, based on a patient's clinical course and condition. Generator removal (GR) alone was performed in several cases in which the infection was limited to the local chest incision and did not track up to the cervical region. When there was evidence of a cervical infection, attempts were made to unwrap the electrode lead from the vagus nerve (total removal [TR]). In cases with extensive scarring, small parts of the spiral electrodes were left in situ to minimize vagus nerve injury (near-total removal [NTR]). Perioperative intravenous antibiotics were held until specimens were collected. Postoperative antibiotics were individualized through discussion with the infectious disease team and thus varied from person to person. Generally, intravenous antibiotics were preferred if fever with or without any other signs or symptoms suggesting bacteremia was present or if any parts of foreign bodies remained in place. A combination of broad-spectrum antibiotics was initially used and then narrowed depending on the causative microorganisms and their sensitivities.

\section{Data Analyses}

Data on patients, therapeutic interventions, surgical morbidities of hardware removal, infection outcomes, and postinfection epilepsy management were collected and studied. Surgical records in all the patients were thoroughly reviewed. Therapeutic interventions for VNS-SSI were categorized as follows, according to their invasiveness: 1) antibiotics with or without percutaneous procedures (aspiration, etc.), 2) nonremoval open procedures (debridement and open irrigation), 3) GR, and 4) NTR or TR. Interventions 1-3 were considered as lead-preservation measures.

\section{Results \\ Baseline Characteristics}

A total of 16 patients were found to have VNS-SSI and thus were included in the study. Detailed baseline characteristics of the patients are summarized in Table 1. Briefly, there were 9 males and 7 females. The mean $( \pm$ standard deviation) age at VNS placement was $28( \pm 11)$ years and the mean BMI was $26( \pm 6) \mathrm{kg} / \mathrm{m}^{2}$. Only 1 patient had diabetes mellitus, and 4 patients $(25 \%)$ were obese as defined by a BMI $>30 \mathrm{~kg} / \mathrm{m}^{2}$. No patient had additional brain hardware including shunts or any other clear infection risk factors. The diagnoses leading to intractable epilepsy included Lennox-Gastaut syndrome $(n=2)$, cortical dysplasia $(n=1)$, Rasmussen's encephalitis $(n=1)$, dysembryoplastic neuroepithelial tumor $(\mathrm{n}=1)$, mesial temporal sclerosis $(n=1)$, microcephaly $(n=1)$, and other refractory seizure without a specified underlining condition (n $=9$ ). All the initial VNS placements were done on the left side. The VNS implantation procedures were complicated in 1 patient (case 8) because of an intraoperative pneumothorax in the contralateral side; this patient had severe chronic global static encephalopathy secondary to microcephaly. The right tension pneumothorax was discovered immediately after the surgery, as his oxygen level dropped significantly. Decompression was performed in the operative suite with chest tube placement. Since the affected side was contralateral, the pneumothorax was thought to be unrelated to the VNS insertion procedure. Another patient (case 3), without any sign of fever, tenderness, drainage, redness, or any other sign suggestive of infection 2 weeks after surgery, developed a postoperative subacute subcutaneous hematoma in the chest, which eventually required needle aspiration 3 weeks following surgery. This case demonstrated a hematoma without purulence; nevertheless, Staphylococcus aureus grew from the culture at that time, which was thought to be contamination. By then, the patient had been without any signs of infection for more than 1 month. However, 2 months following surgery, the patient was found to have wound dehiscence and thus underwent hardware removal. Both patients had demonstrated self-mutilating behavior and thus tended to scratch at their incisions. 


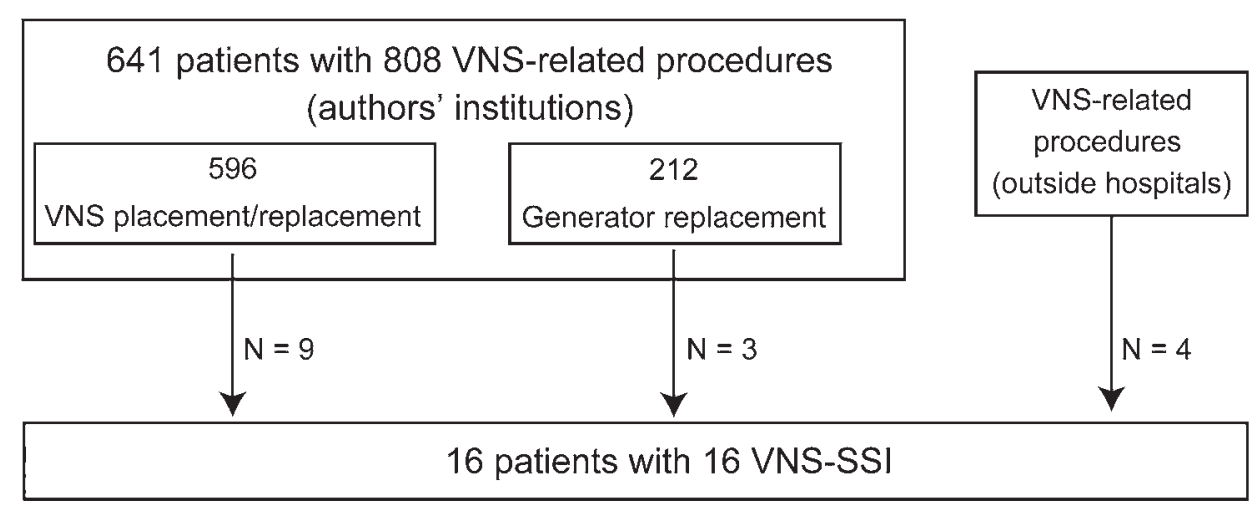

FIG. 1. A flowchart of case accumulation in the present study.

\section{Establishment of VNS-SS}

Among the 16 cases of VNS-SSI, 11 occurred after initial VNS placement and 5 occurred after generator replacement, with 2 of the former and 2 of the latter having undergone the original surgery leading to infection at an outside hospital (Fig. 1). Therefore, the incidence of infection for surgeries performed at our institutions was $1.5 \%$ (12/808). Among the institutional cases, the incidence of VNS-SSI did not differ between whole system placement and generator replacement (1.5\% [9/596] and 1.4\% [3/212], respectively, $\mathrm{p}=0.99$, Fisher's exact test). The mean time to VNS-SSI was $42( \pm 27)$ days from the most recent VNSrelated surgery and $681( \pm 1360)$ days from initial placement. Wound dehiscence, redness, swelling, and drainage were the typical symptoms of VNS-SSI; occasionally, wound breakdown with exposure of hardware was the presenting symptom (Table 1). The data on causative bacteria were available in 12 patients; methicillin-sensitive staphylococcus (MSS) was identified in 7 patients (58\%), methicillin-resistant $S$. aureus in 1 (8\%), and unspecified gram-positive coccus in 1 (8\%). In 1 patient with MSS, Enterobacter and Pseudomonas were also identified. Culture was negative in 2 patients (17\%).

\section{Actual Management for VNS-SSI}

The therapeutic interventions against VNS-SSI are summarized in Table 2. The mean follow-up period from the procedure/surgery for VNS-SSI to the last clinical visit was $80( \pm 52)$ months. Five neurosurgeons were involved in the treatment of VNS-SSI; lead-preservation measures were initially taken in 12 patients, including antibiotics with or without percutaneous procedures in 6 , debridement and irrigation in 3 , and GR in 3, whereas direct TR or NTR was initially performed in 4 patients. The lead-preservation measures were successful in 1 patient exclusively after 20 days of oral antibiotics in whom the chest incision had revealed a $2-\mathrm{cm}$ superficial opening with some erythema without any fluid collection (the deeper layer seemed to be uncontaminated) and in 1 patient after GR with a subsequent 4 weeks of intravenous antibiotic therapy; all of the other 14 patients required TR or NTR. Overall, NTR was performed in 3 patients, and VNS-SSI was cleared in 2 of them; the third patient (case 12) had recurrent infection despite a subsequent 8 weeks of antibiotic therapy and thus required TR. Overall, TR was performed in 12 patients; VNS-SSI was eventually cleared in all of them, including 1 patient who had developed a large pectoral abscess and needed revision debridement and irrigation because of a recurrent chest pocket infection.

The success rate of each treatment was as follows: 17\% $(1 / 6)$ for antibiotics with or without percutaneous procedures, $0 \%(0 / 4)$ for debridement and irrigation, $20 \%(1 / 5)$ for GR, $67 \%$ (2/3) for NTR, and 100\% (12/12) for TR. Satisfactory infection control was finally achieved in all the patients. The postoperative complications included mild hoarseness and difficulty/discomfort with swallowing in 2 patients who had undergone TR (2/12 [17\%]), which was fully cleared in both patients within a year. Intraoperative laceration of the jugular vein occurred in 1 patient in whom TR had been attempted, which was successfully controlled without any neurological or nonneurological sequelae. This patient ended up going no further than NTR. Otherwise, no perioperative complication or death was observed.

\section{Epilepsy Management After VNS Infection}

The intensity and frequency of seizures were unchanged after clinical confirmation of VNS-SSI as long as the VNSs remained on, though the observation period was too short in 4 patients, as their VNSs were removed either partially or totally right after the VNS-SSI was evident. Also, 1 patient developed VNS-SSI before the system was activated.

One patient without hardware removal remained on vagus nerve stimulation; in the other patients, seizure control went back to their baseline level once the VNS was removed. After the removal, 13 patients were managed medically, whereas repeat VNS placement was performed in 2 patients in whom stimulation had been quite effective, following an extensive discussion with the infectious disease team. The times from surgical removal to the repeat placement were 25 and 185 days, respectively. With support from head and neck surgeons, the placement was successfully done on the left side (infected side) without complication in all the patients. An additional 7- to 10-day course of oral cephalexin was given on top of the standard perioperative intravenous antibiotics. During the followup period of 124 and 167 months thereafter, those patients were free from subsequent infection. 
TABLE 1. Characteristics of patients with VNS-related infections

\begin{tabular}{|c|c|c|c|c|c|c|c|c|c|c|}
\hline $\begin{array}{l}\text { Case } \\
\text { No. }\end{array}$ & $\begin{array}{l}\text { Age } \\
\text { (yrs), } \\
\text { Sex }\end{array}$ & DM & Smoking & $\begin{array}{c}\mathrm{BMI} \\
\left(\mathrm{kg} / \mathrm{m}^{2}\right)^{*}\end{array}$ & $\begin{array}{l}\text { PSx for } \\
\text { Epilepsy }\end{array}$ & $\begin{array}{l}\text { Complication at } \\
\text { Initial Implantation }\end{array}$ & $\begin{array}{l}\text { Infection } \\
\text { Symptoms }\end{array}$ & $\begin{array}{l}\text { Origin of } \\
\text { Infection }\end{array}$ & $\begin{array}{l}\text { Days From Most } \\
\text { Recent VNS-Related } \\
\text { Surgery to Infection }\end{array}$ & $\begin{array}{l}\text { Infection } \\
\text { After Initial } \\
\text { Implantation }\end{array}$ \\
\hline 1 & $50, F$ & Yes & Yes & 38 & $\begin{array}{l}\text { Temporal } \\
\text { lobectomy }\end{array}$ & - & $\begin{array}{l}\text { Wound dehiscence, } \\
\text { redness, drainage }\end{array}$ & Chest & 27 & Yes \\
\hline 2 & $26, F$ & No & Yes & 20 & $\begin{array}{l}\text { Subdural } \\
\text { electrodes }\end{array}$ & - & $\begin{array}{l}\text { Wound dehiscence, } \\
\text { redness, drainage }\end{array}$ & Neck & 51 & Yes \\
\hline 3 & $40, M$ & No & No & 26 & None & $\begin{array}{l}\text { Postop subcutaneous } \\
\text { hematoma } 3 \text { wks later }\end{array}$ & $\begin{array}{l}\text { Wound dehiscence, } \\
\text { redness, drainage }\end{array}$ & Neck & 79 & Yes \\
\hline 4 & $17, M$ & No & No & 26 & $\begin{array}{l}\text { Temporal } \\
\text { lobectomy }\end{array}$ & - & $\begin{array}{l}\text { Redness, wound } \\
\text { dehiscence, exposed } \\
\text { generator }\end{array}$ & Chest & 18 & No \\
\hline 5 & $31, F$ & No & No & 35 & None & $-\dagger$ & Wound dehiscence & Chest & 92 & Yes \\
\hline 6 & $23, F$ & No & No & 19 & ND & - & $\begin{array}{l}\text { Redness, swelling, } \\
\text { drainage }\end{array}$ & Chest & 17 & Yes \\
\hline 7 & $13, F$ & No & No & 20 & $\begin{array}{l}\text { Subdural } \\
\text { electrodes }\end{array}$ & - & $\begin{array}{l}\text { Drainage from both cra- } \\
\text { nial \& neck incisions }\end{array}$ & Neck & 34 & Yes \\
\hline 8 & $37, \mathrm{M}$ & No & No & 18 & ND & Pneumothorax & $\begin{array}{l}\text { Wound dehiscence, } \\
\text { exposed tie-down }\end{array}$ & Neck & 76 & Yes \\
\hline 9 & $35, M$ & No & No & 29 & SEEG & - & $\begin{array}{l}\text { Wound dehiscence, } \\
\text { redness, swelling, } \\
\text { drainage }\end{array}$ & Chest & 10 & No \\
\hline 10 & $22, \mathrm{M}$ & No & Yes & 20 & $\begin{array}{l}\text { Temporal } \\
\text { lobectomy }\end{array}$ & - & Redness, swelling & Neck & 80 & Yes \\
\hline 11 & $15, F$ & No & No & 33 & None & - & $\begin{array}{l}\text { Wound dehiscence, } \\
\text { redness, drainage }\end{array}$ & Chest & 14 & Yes \\
\hline 12 & $43, M$ & No & Yes & 31 & RNS, MST & - & Swelling & Chest & 31 & Yes \\
\hline 13 & $18, \mathrm{M}$ & No & No & 23 & None & $\mathrm{ND} \dagger$ & ND & ND & 33 & No \\
\hline 14 & $33, F$ & No & No & ND & None & ND† & Pain, discomfort, drainage & Chest & 23 & Yes \\
\hline 15 & $30, M$ & No & No & 25 & None & ND† & Redness, swelling & Chest & 34 & No \\
\hline 16 & $15, M$ & No & No & 21 & None & - & $\begin{array}{l}\text { Wound dehiscence, } \\
\text { exposed generator }\end{array}$ & Chest & 36 & No \\
\hline
\end{tabular}

$\mathrm{DM}=$ diabetes mellitus; $\mathrm{MST}$ = multiple subpial transection; $\mathrm{ND}$ = no data; $\mathrm{PSx}$ = previous surgery; RNS = responsive neurostimulation; $\mathrm{SEEG}=$ stereoelectroencephalography . * At the time of VNS placement.

$\dagger$ Done at an outside hospital.

\section{Discussion}

To date, several reports have described VNS-related infection; most of them are case reports or small case series or briefly describe VNS-SSI as part of comprehensive studies including 10 or fewer patients (Table 3).17,20, 26-32 In the present study, we analyzed in detail 16 patients with VNS-SSI according to our large-volume database, which included 808 VNS hardware placement surgeries, describing the clinical characteristics of VNS-SSI and focusing on the outcomes of both nonsurgical and surgical interventions as well as their complications. Overall, the incidence of VNS-SSI in the present study was $1.5 \%$, which is slightly less than previous reports but within variance. ${ }^{3,17-19,26,27,31,32}$ If VNS-SSI was appropriately managed, it did not result in severe neurological sequelae or death in our cohort. VNS-SSI mostly occurred within 3 months from the initial placement or generator replacement; special attention should be provided if a patient develops any signs of infection within this time period, including de- hiscence, redness, swelling, fluid collection, and drainage. Infection can arise from both the chest and neck incision; our data showed a mild inclination toward a chest origin (67\% vs 33\%), and in fact, some studies have shown a similar trend. ${ }^{20,26,27}$ However, this finding may be simply attributable to the greater number of interventions performed at the site of chest incision given the need for generator replacement. In our cohort, 1 patient (case 3) developed a postoperative hematoma and another patient (case 8) developed pneumothorax. The hematoma required a needle aspiration; thus, there is a possibility that contamination could have occurred as a result of that intervention. Regarding the contralateral pneumothorax, there was no convincing evidence indicating an association with infection. Notably, both patients had exhibited self-mutilating behavior and tended to scratch their incision, which may have been associated with the infection.

Given our findings, we summarized an optimal treatment algorithm for VNS-SSI (Fig. 2). Regarding the ini- 


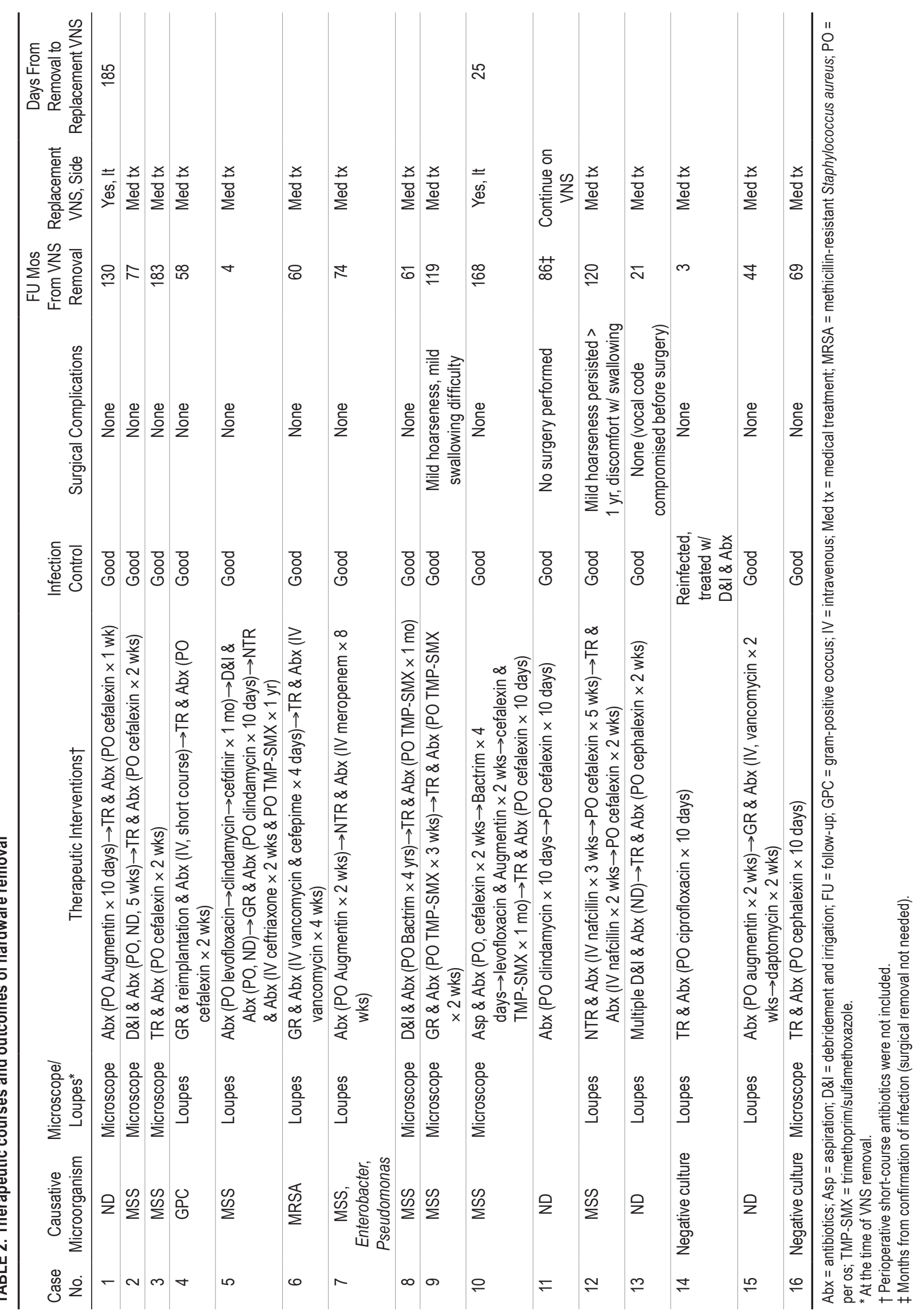


TABLE 3. Literature review of studies describing VNS infection

\begin{tabular}{|c|c|c|c|c|c|c|c|c|c|}
\hline \multirow[b]{2}{*}{$\begin{array}{l}\text { Authors } \\
\& \text { Year }\end{array}$} & \multirow[b]{2}{*}{$\begin{array}{l}\text { No. of } \\
\text { Cases }\end{array}$} & \multirow[b]{2}{*}{$\begin{array}{l}\text { Incidence of } \\
\text { Infection }\end{array}$} & \multirow{2}{*}{$\begin{array}{l}\text { Time From } \\
\text { Recent } \\
\text { VNS-Related } \\
\text { Procedures } \\
\text { to Infection }\end{array}$} & \multicolumn{3}{|c|}{$\begin{array}{c}\text { Attempts for Lead-Preservation No.* } \\
\text { [no. requiring TR/NTR] }\end{array}$} & \multirow[b]{2}{*}{$\begin{array}{l}\text { Final } \\
\text { Extent of } \\
\text { Removal }\end{array}$} & \multirow[b]{2}{*}{$\begin{array}{l}\text { Surgical } \\
\text { Morbidities }\end{array}$} & \multirow[b]{2}{*}{$\begin{array}{l}\text { FU After } \\
\text { Interventions } \\
\text { for Infection }\end{array}$} \\
\hline & & & & $\begin{array}{l}\text { Abx w/ or w/o } \\
\text { Nonremoval } \\
\text { Procedures }\end{array}$ & $\begin{array}{l}\text { GR (directly } \\
\text { or after } \\
\text { failed } A b x \text { ) }\end{array}$ & $\begin{array}{c}\text { Directly } \\
\text { Proceeded } \\
\text { by TR/NTR }\end{array}$ & & & \\
\hline $\begin{array}{l}\text { Révész et al., } \\
2016^{17}\end{array}$ & 10 & $\begin{array}{l}0.8 \%(1990-1999) \\
3.3 \%(2000-2014)\end{array}$ & 99 days & $10[8]$ & $5[2]$ & 3 & $\begin{array}{c}\text { None 2, } \\
\text { GR 3, TR } 5\end{array}$ & None & NA \\
\hline $\begin{array}{l}\text { Wozniak et al., } \\
2011^{26}\end{array}$ & 6 & $2.9 \%$ & $1-8$ wks & & $4[1]$ & 2 & GR 3, TR 3 & NA & $\begin{array}{c}10 \text { mos, } 5.5 \\
\text { yrs, } 7.5 \text { yrs } \\
\text { after GR }\end{array}$ \\
\hline $\begin{array}{l}\text { Elliott et al., } \\
2011^{130}\end{array}$ & 9 & NA & NA & NA & NA & NA & $\begin{array}{l}\text { None 2, } \\
\text { TR } 7\end{array}$ & None & NA \\
\hline Air et al., $2009^{27}$ & 10 & $5.2 \%$ & 29.8 days & $7[5]$ & & 3 & $\begin{array}{l}\text { None 2, } \\
\text { TR/NTR } 8\end{array}$ & None & NA \\
\hline $\begin{array}{l}\text { Liechty et al., } \\
2006^{29}\end{array}$ & 1 & NA & NA & & $1 \mp[0]$ & & GR 1 & None & NA \\
\hline $\begin{array}{l}\text { Patel \& } \\
\text { Edwards, } 2004^{20}\end{array}$ & 3 & NA & 9-37 days & $2[2]$ & $1[1]$ & 1 & TR 3 & NA & NA \\
\hline $\begin{array}{l}\text { Smyth et al., } \\
2003^{32}\end{array}$ & 6 & $7.1 \%$ & $<4$ wks & $3[0]$ & & 3 & $\begin{array}{l}\text { None 3, } \\
\text { TR } 3\end{array}$ & NA & NA \\
\hline $\begin{array}{l}\text { Ortler et al., } \\
2001^{28}\end{array}$ & 1 & NA & 5 wks & & $1[1]$ & & TR 1 & None & NA \\
\hline $\begin{array}{l}\text { Murphy et al., } \\
1998^{31}\end{array}$ & 1 & $4.2 \%$ & $3 \mathrm{mos}$ & $1[1]$ & & & TR 1 & NA & 38 days \\
\hline Present study & 16 & $1.5 \%$ & 42 days & $9[8]$ & $5[4]$ & 4 & $\begin{array}{l}\text { None 1, } \\
\text { GR 1, TR/ } \\
\text { NTR } 14\end{array}$ & $\begin{array}{l}\text { Mild swallowing } \\
\text { problem w/ hoarse- } \\
\text { ness, } 2 / 12 \text { TR }\end{array}$ & 80 mos \\
\hline
\end{tabular}

NA = not assessed.

* There may be overlap between "Abx with or without nonremoval procedures" and "GR."

$\dagger$ Time from implantation to surgery due to infection, wound revision, or explantation.

$\ddagger$ Battery replacement with concomitant use of sump antibiotic irrigation system.

tial treatment, some studies have argued that VNS-SSI can be managed solely with antibiotics..$^{17,19,27,30,32}$ Indeed, in our cohort, infection was cleared with antibiotics alone in only 1 patient, suggesting that empirical antibiotic therapy may prevent propagation of infection if it stays superficial and local. Also, despite a low ultimate rate of success with antibiotic treatment alone, attempting antibiotic treatment before escalating the intervention to hardware removal did not appear to be associated with an increase in complications. Therefore, antibiotic monotherapy would be a reasonable prehospital option when infection seems superficial and localized at one incision site. In such cases, however, longer observation should be mandated, as infection can recur even $>1$ year after the initiation of therapy. ${ }^{27}$ Because most VNS-SSIs are caused by pan-sensitive MSS, ${ }^{26,27}$ there are multiple options for an appropriate antibiotic choice. Since we have not aggressively attempted nonsurgical management, intensive antibiotic therapies may show a better success rate to save hardware than our results. This is worth evaluation in future studies.

If infection extends to VNS hardware, removal of that hardware is recommended, as infection, in fact, persisted in all cases that had nonremoval management. Regarding the extent of removal, GR alone appears to have a low success rate and should be cautiously considered perhaps with an extended trial of antibiotics. Some authors have suggested lead-preserving procedures in conjunction with an intensive antibiotic regimen and repeat local irrigation. ${ }^{26-29}$ However, these recommendations are based on case reports or small case series and thus require further research to more firmly establish their efficacy and safety.

Complete hardware removal including the electrode is the definitive treatment, as confirmed in this report. On the other hand, the incidence of transient vocal cord/swallowing problems was $17 \%$ after TR and $0 \%$ after NTR. In fact, removal/replacement attributable to noninfectious reasons has been reported to be as high as 33\%.9,33-37 Fortunately, these problems were cleared within a year in our patients. Given our experience, we recommend the surgeon attempt complete VNS removal, but if scarring around the vagus nerve is prohibitive, it is prudent and safer to snip the electrode close to the nerve, irrigate copiously with antibiotic-containing saline, and then resort to antibiotics as advised by the infectious disease team. This approach has worked well and limits the risk of significant nerve injury. We should also reiterate the importance of pursuing the standard management of foreign body in- 


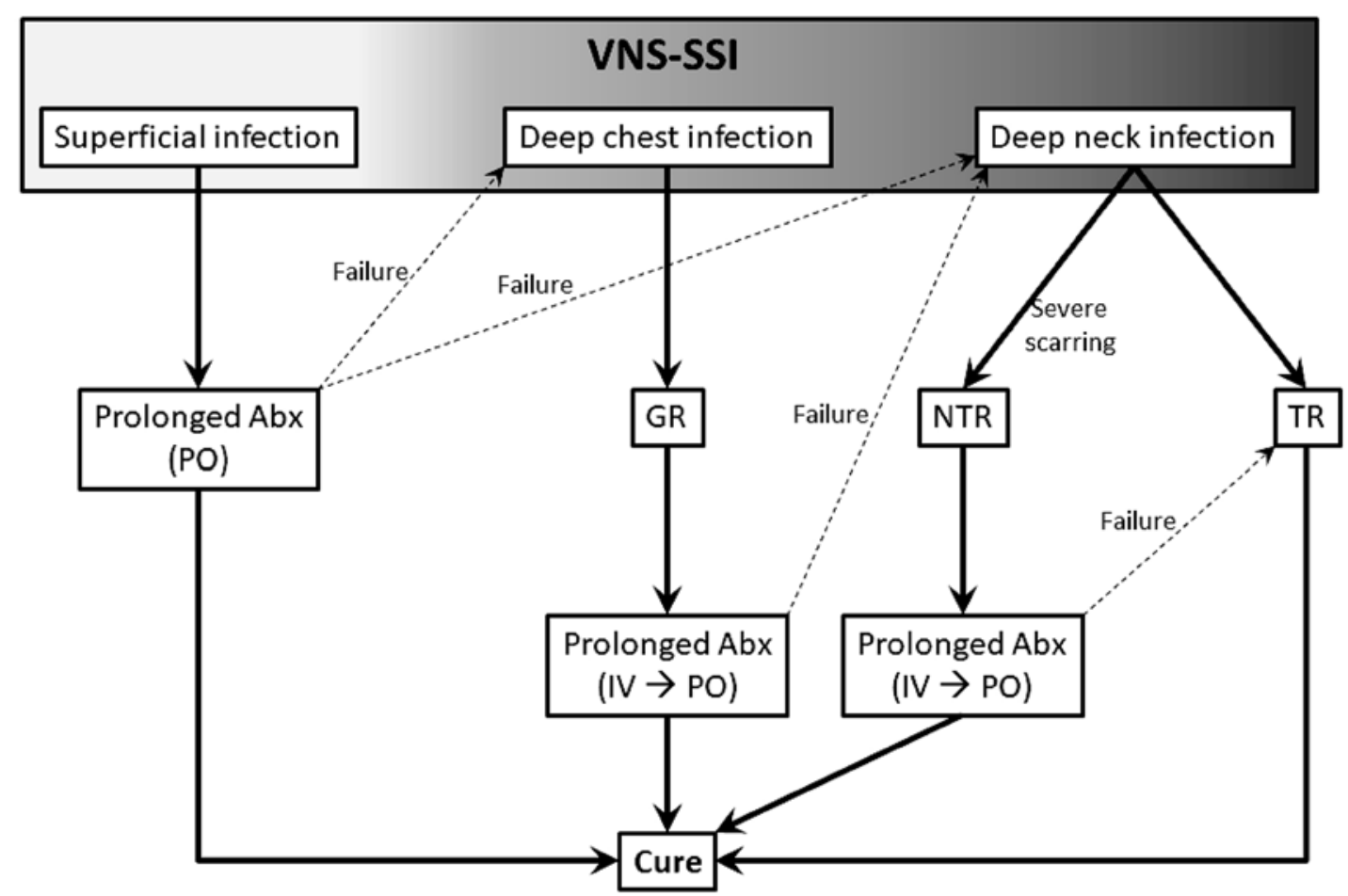

FIG. 2. A proposed treatment algorithm for VNS-SSI is shown. As long as the infection is limited to the superficial layer and does not reach the hardware, it would be plausible to manage it medically with oral (PO) antibiotics (Abx). Physicians may perform needle aspiration to determine whether purulence is present. If the patient develops any signs of deep infection, such as significant continuous drainage, purulence, fever, exposed hardware, or any other signs suggestive of bacteremia, hardware removal should be considered. Generator removal (GR) could be considered if only the chest incision is involved; however, it should be explained to the patient that the ultimate probability of cure is not high and that the patient will need a prolonged course of intravenous (IV) Abx followed by oral therapy. Total removal (TR) is recommended in cases of deep neck infection; however, near-total removal (NTR) with snipping of the leads as close to the vagus nerve as possible can be considered if there is concern about the possibility of extensive scarring around the nerve. Similar to GR, NTR would require a postoperative intensive Abx regimen. Given our experience, debridement and irrigation may not be recommended because of the extremely high rate of failure.

fection on top of hardware removal, including sufficient debridement, copious irrigation, minimizing dead space by placing a drain and applying appropriate compression, and the perioperative use of appropriate antibiotics with sufficient bacterial coverage. In cases of recurrent infection after TR, meticulous re-debridement and irrigation would be recommended.

The feasibility of repeat VNS placement in the setting of a preceding infection is yet to be determined. Our small number of cases suggests that repeat placement can be safely done once infection is completely cleared. Therefore, it can be considered for those in whom VNS is known to be highly effective, especially if their epilepsy control worsens following VNS removal. Though we did not observe vocal cord palsy, its risk in VNS revision is reported to be slightly higher than that in a first implantation. ${ }^{9}$ Regarding the timing, repeat VNS placement was successfully performed at around 1 month from hardware removal in 1 patient in the present cohort, suggesting that early placement may be possible if TR is done and followed by appropriate postoperative antibiotic therapy; however, this number is too small to draw any conclusions. Right-sided placement is a possible alternative, ${ }^{38-40}$ and indeed, it may be necessary if reimplantation needs to be done in a patient after NTR (in whom the vagus nerve leads would remain in place). However, close follow-up and cardiac monitoring would be desirable for possible cardiac side effects, and preoperative assessment of vocal cord function is important to avoid the risk of bilateral vocal cord palsy. In theory, the battery could be placed in the right side while the leads are placed in the left side if right-sided battery placement is deemed inappropriate. In summary, the timing and side of placement should be determined after due consideration of the above-mentioned points.

This study has several limitations. First, although it reports the largest number of VNS-SSI cases with over 800 VNS-related surgery cases examined, VNS-SSI was uncommon, occurring in only 16 patients. Second, there may have been patients who were treated at an outside hospital, which could have resulted in an underestimation of the incidence of VNS-SSI; however, that number is likely very small, as the infection rate in our study was similar to previously published rates. Third, the most important management of VNS-SSI is primary prevention. Therefore, determining those at greatest risk would be important and should be the subject of future research. 


\section{Conclusions}

VNS-SSI is a rare but significant complication of VNS implantation. Our data demonstrate that in cases other than a localized superficial site infection, it is best to surgically remove as much of the VNS apparatus as safety permits. If there is dense scarring at the vagus nerve electrode wrap, then it is prudent to leave the spiral electrodes in situ and treat aggressively with antibiotics.

\section{References}

1. Wheless JW, Gienapp AJ, Ryvlin P. Vagus nerve stimulation (VNS) therapy update. Epilepsy Behav. 2018;88S:2-10.

2. Spencer $S$, Huh L. Outcomes of epilepsy surgery in adults and children. Lancet Neurol. 2008;7(6):525-537.

3. DeGiorgio CM, Schachter SC, Handforth A, et al. Prospective long-term study of vagus nerve stimulation for the treatment of refractory seizures. Epilepsia. 2000;41(9): $1195-1200$.

4. Usami K, Kawai K, Sonoo M, Saito N. Scalp-recorded evoked potentials as a marker for afferent nerve impulse in clinical vagus nerve stimulation. Brain Stimul. 2013;6(4):615-623.

5. Amar AP, Heck CN, Levy ML, et al. An institutional experience with cervical vagus nerve trunk stimulation for medically refractory epilepsy: rationale, technique, and outcome. Neurosurgery. 1998;43(6):1265-1280.

6. Englot DJ, Rolston JD, Wright CW, et al. Rates and predictors of seizure freedom with vagus nerve stimulation for intractable epilepsy. Neurosurgery. 2016;79(3):345-353.

7. Elliott RE, Morsi A, Tanweer O, et al. Efficacy of vagus nerve stimulation over time: review of 65 consecutive patients with treatment-resistant epilepsy treated with VNS > 10 years. Epilepsy Behav. 2011;20(3):478-483.

8. Connor DE Jr, Nixon M, Nanda A, Guthikonda B. Vagal nerve stimulation for the treatment of medically refractory epilepsy: a review of the current literature. Neurosurg Focus. 2012;32(3):E12.

9. Giordano F, Zicca A, Barba C, et al. Vagus nerve stimulation: surgical technique of implantation and revision and related morbidity. Epilepsia. 2017;58(suppl 1):85-90.

10. Kawai K, Tanaka T, Baba H, et al. Outcome of vagus nerve stimulation for drug-resistant epilepsy: the first three years of a prospective Japanese registry. Epileptic Disord. 2017;19(3): 327-338.

11. García-Pallero MA, García-Navarrete E, Torres CV, et al. Effectiveness of vagal nerve stimulation in medicationresistant epilepsy. Comparison between patients with and without medication changes. Acta Neurochir (Wien). 2017; 159(1):131-136.

12. Kawai K, Shimizu H, Maehara T, Murakami H. Outcome of long-term vagus nerve stimulation for intractable epilepsy. Neurol Med Chir (Tokyo). 2002;42(11):481-490.

13. Conway CR, Sheline YI, Chibnall JT, et al. Cerebral blood flow changes during vagus nerve stimulation for depression. Psychiatry Res. 2006;146(2):179-184.

14. Conway CR, Sheline YI, Chibnall JT, et al. Brain blood-flow change with acute vagus nerve stimulation in treatment-refractory major depressive disorder. Brain Stimul. 2012;5(2):163-171.

15. Zobel A, Joe A, Freymann N, et al. Changes in regional cerebral blood flow by therapeutic vagus nerve stimulation in depression: an exploratory approach. Psychiatry Res. 2005; 139(3):165-179.

16. Conway CR, Xiong W. The mechanism of action of vagus nerve stimulation in treatment-resistant depression: current conceptualizations. Psychiatr Clin North Am. 2018;41(3):395-407.

17. Révész D, Rydenhag B, Ben-Menachem E. Complications and safety of vagus nerve stimulation: 25 years of experience at a single center. J Neurosurg Pediatr. 2016;18(1):97-104.
18. Ramsay RE, Uthman BM, Augustinsson LE, et al. Vagus nerve stimulation for treatment of partial seizures: 2. Safety, side effects, and tolerability. Epilepsia. 1994;35(3):627-636.

19. Ben-Menachem E. Vagus nerve stimulation, side effects, and long-term safety. J Clin Neurophysiol. 2001;18(5):415-418.

20. Patel NC, Edwards MS. Vagal nerve stimulator pocket infections. Pediatr Infect Dis J. 2004;23(7):681-683.

21. Patwardhan RV, Stong B, Bebin EM, et al. Efficacy of vagal nerve stimulation in children with medically refractory epilepsy. Neurosurgery. 2000;47(6):1353-1358.

22. Yu C, Ramgopal S, Libenson M, et al. Outcomes of vagal nerve stimulation in a pediatric population: a single center experience. Seizure. 2014;23(2):105-111.

23. Kabir SM, Rajaraman C, Rittey C, et al. Vagus nerve stimulation in children with intractable epilepsy: indications, complications and outcome. Childs Nerv Syst. 2009;25(9): 1097-1100.

24. Galbarriatu L, Pomposo I, Aurrecoechea J, et al. Vagus nerve stimulation therapy for treatment-resistant epilepsy: a 15-year experience at a single institution. Clin Neurol Neurosurg. 2015;137:89-93.

25. Fernandez L, Gedela S, Tamber M, Sogawa Y. Vagus nerve stimulation in children less than 3 years with medically intractable epilepsy. Epilepsy Res. 2015;112:37-42.

26. Wozniak SE, Thompson EM, Selden NR. Vagal nerve stimulator infection: a lead-salvage protocol. J Neurosurg Pediatr. 2011;7(6):671-675.

27. Air EL, Ghomri YM, Tyagi R, et al. Management of vagal nerve stimulator infections: do they need to be removed? $J$ Neurosurg Pediatr. 2009;3(1):73-78.

28. Ortler M, Luef G, Kofler A, et al. Deep wound infection after vagus nerve stimulator implantation: treatment without removal of the device. Epilepsia. 2001;42(1):133-135.

29. Liechty PG, Tubbs RS, Blount JP. The use of a sump antibiotic irrigation system to save infected hardware in a patient with a vagal nerve stimulator: technical note. Surg Neurol. 2006;65(1):48-50.

30. Elliott RE, Morsi A, Kalhorn SP, et al. Vagus nerve stimulation in 436 consecutive patients with treatment-resistant epilepsy: long-term outcomes and predictors of response. Epilepsy Behav. 2011;20(1):57-63.

31. Murphy JV, Hornig GW, Schallert GS, Tilton CL. Adverse events in children receiving intermittent left vagal nerve stimulation. Pediatr Neurol. 1998;19(1):42-44.

32. Smyth MD, Tubbs RS, Bebin EM, et al. Complications of chronic vagus nerve stimulation for epilepsy in children. $J$ Neurosurg. 2003;99(3):500-503.

33. Rychlicki F, Zamponi N, Cesaroni E, et al. Complications of vagal nerve stimulation for epilepsy in children. Neurosurg Rev. 2006;29(2):103-107.

34. Aalbers MW, Rijkers K, Klinkenberg S, et al. Vagus nerve stimulation lead removal or replacement: surgical technique, institutional experience, and literature overview. Acta Neurochir (Wien). 2015;157(11):1917-1924.

35. Ortler M, Unterhofer C, Dobesberger J, et al. Complete removal of vagus nerve stimulator generator and electrodes. $J$ Neurosurg Pediatr. 2010;5(2):191-194.

36. Vassilyadi M, Strawsburg RH. Delayed onset of vocal cord paralysis after explantation of a vagus nerve stimulator in a child. Childs Nerv Syst. 2003;19(4):261-263.

37. Couch JD, Gilman AM, Doyle WK. Long-term expectations of vagus nerve stimulation: a look at battery replacement and revision surgery. Neurosurgery. 2016;78(1):42-46.

38. McGregor A, Wheless J, Baumgartner J, Bettis D. Rightsided vagus nerve stimulation as a treatment for refractory epilepsy in humans. Epilepsia. 2005;46(1):91-96.

39. Navas M, Navarrete EG, Pascual JM, et al. Treatment of refractory epilepsy in adult patients with right-sided vagus nerve stimulation. Epilepsy Res. 2010;90(1-2):1-7. 
40. Spuck S, Nowak G, Renneberg A, et al. Right-sided vagus nerve stimulation in humans: an effective therapy? Epilepsy Res. 2008;82(2-3):232-234.

\section{Disclosures}

B.N.L. is a named inventor for intellectual property licensed to Cadence Neuroscience Inc., which is co-owned by the Mayo Clinic. B.N.L. has waived contractual rights to royalties. B.N.L. is an investigator for the Medtronic Deep Brain Stimulation Therapy for Epilepsy Post-Approval Study (EPAS). B.N.L. is an investigator for Mayo Clinic Medtronic NIH Public Private Partnership (UH3-NS95495).

\section{Author Contributions}

Conception and design: Hasegawa. Acquisition of data: Hasegawa. Analysis and interpretation of data: Hasegawa. Drafting the article: Hasegawa. Critically revising the article: Meyer, Van Gompel, Marsh, Wharen. Reviewed submitted version of manuscript: Van
Gompel, Marsh, Wharen, Zimmerman, Burkholder, Lundstrom, Britton. Approved the final version of the manuscript on behalf of all authors: Meyer. Statistical analysis: Hasegawa. Study supervision: Meyer, Van Gompel.

\section{Correspondence}

Fredric B. Meyer: Mayo Clinic, Rochester, MN. meyer.fredric@ mayo.edu. 